\title{
La función pública, organización y direccionamiento: fundamento esencial en la administración pública
}

\author{
Héctor Turizo Tapias ${ }^{1}$
}

\begin{abstract}
Resumen
La presente temática examina lo referente al lugar que ocupa la función pública en la organización y direccionamiento dentro de la administración pública, en su compromiso constitucional de responder al cumplimiento de los fines y fines esenciales del Estado, eje de su actividad, buscando la importante y suficiente articulación y gestión entre el empleo público y las personas que lo integran. Para ello argumentamos analíticamente las normatividades al respecto, las recomendaciones de tratadistas en el tema, los manuales de funciones como herramienta de gestión de talento humano y la Carta Iberoamericana de la función pública. Este compromiso origina tanta importancia para la administración pública, puesto que la función pública ocupa en nuestra Constitución poco más de la mitad de sus artículos, por lo que se procura detallar no solo la función pública en sí, sino, el fundamento esencial que ella contiene dentro de la administración pública para alcanzar los fines.
\end{abstract}

\section{Palabras Claves}

Función pública, empleo, funciones, fines esenciales, poder, competencias laborales, administración pública

\begin{abstract}
The present topic examines the place of the public function in the organization and direction within the public administration, in its constitutional commitment to respond to the fulfillment of the essential ends and purposes of the State, axis of its activity, seeking the important and sufficient articulation and management between public employment and the people that comprise it. For this, we analytically argue the regulations in this regard, the recommendations of writers on the subject, the manuals of functions as a tool for managing human talent and the Ibero-American Charter of the public function. This commitment is of such importance for the public administration, since the public function occupies in our Constitution a little more than half of its articles, so it seeks to detail not only the public function itself, but the essential foundation that it contains within the public administration to achieve the ends.
\end{abstract}

\section{Keywords}

Civil Service, Employment, functions, essential goals, power, labor skills, public administration 


\section{Introducción}

El siguiente trabajo tiene como objetivo comprender el fundamento esencial de la Función Pública como organización y direccionamiento dentro de la administración pública como eje de la actividad del Estado, para lo cual es necesario allegar, con fundamento, lo concerniente a dicha función en lo que respecta a la operatividad sincronizada Empleo - Funciones y las relaciones laborales entre el Estado y los servidores públicos, con la finalidad de ejecutar los fines esenciales del Estado.

En estos últimos años se ha despertado en la sociedad civil un interés hacia el estudio de la Administración Pública como compromiso y responsabilidad democrática, para alcanzar las finalidades esenciales del Estado mediante una gestión desde el poder que responda a las demandas de la comunidad. En efecto, uno de los aspectos de más interés dentro de la administración pública, lo constituye indudablemente la función pública, la cual como parte neural en la ejecución de dicha administración, en sentido concreto involucra el conjunto de principios, instituciones, reglas y procedimientos que el Estado en su actividad ejercita, por ello la Carta Iberoamericana de la función Pública recomienda que para "la consecución de un mejor Estado, instrumento indispensable para el desarrollo de los países, la profesionalización de la función pública es una condición necesaria".

Bajo los anteriores principios se empieza a comprender la magnitud de la función pública dentro de la administración pública, como la actividad del Estado en sentido general, pues ello involucra a todas las instituciones para que en su conjunto muestren una administración pública dirigida al cumplimiento de los fines del Estado. Se señala entonces, en base al principio clásico de la se- paración de poderes, que la función pública es inherente a la actividad de las ramas del poder público. Cabe anotar de igual manera los órganos autónomos e independientes, para el cumplimiento de las demás funciones del Estado (Art. 113 C.P.).

De otro lado se detallarán los alcances de esa función, realizando un recorrido por las normatividades que la posicionan, con el fin de aproximarnos a ese fundamento esencial que porta la función pública dentro de la administración pública. Posteriormente, se analizan sus deficiencias en la operatividad que de ella tenga la burocracia del Estado para poder indefectiblemente lograr los fines esenciales del Estado.

Por tales razones, el desarrollar la citada temática es materia de mucho interés, y en este sentido se orienta el presente trabajo para tratar sobre el fundamento esencial de la función pública dentro de la administración pública, partiendo de referentes teóricos, alternando los manuales específicos de funciones y competencias laborales, cuyas funciones son función pública, el empleo, que existe bajo unas funciones específicas, el servidor público que debe cumplir esas funciones como actividad del Estado, los cuales para efectos de este trabajo llamaremos elementos y la administración pública, que de hecho, debe buscar la finalidad del Estado, señalando de paso el problema jurídico que se genera cuando esa administración en su comportamiento, no actúa bajo principios acordes a un Estado social de derecho y por supuesto no cumple los fines del Estado.

\section{Referentes teóricos de la función pública}

En nuestro país en materia de función pública, existe el Departamento Administrativo de la Función Pública - DAFP, pues le corresponde formular las políticas generales de Administración 


\section{Héctor Turizo Tapias}

Pública, en especial en materias relacionadas con Empleo Público, Organización Administrativa, Control Interno y Racionalización de Trámites de la Rama Ejecutiva del Poder Público conforme al Decreto 188 de 26 de enero de 2004 y de igual manera existe un establecimiento público universitario, la Escuela Superior de Administración Pública - ESAP, la cual se encuentra adscrita a dicho Departamento y conforme al artículo $4^{\circ}$ del citado Decreto, el DAFP y la ESAP integran el Sector Administrativo de la Función Pública. Muy claro queda entonces, en manos de quien reposa lo concerniente a la organización y direccionamiento de la función pública en nuestra Colombia

Empezando por desglosar el Término función pública, en su histórico recorrido en el Estado Español, difiere entre lo que fue el Estado monárquico y lo que hoy se entiende como Estado Constitucional.

En cuanto al primer Estado, la Función Pública era considerada como un derecho del Rey, el de nombrar y separar a los servidores públicos. Los puestos u oficios eran creados por el Rey sin restricción alguna. Se requería idoneidad y capacidad, sin embargo no se permitía la cooptación familiar.

En el Estado constitucional se regula el fenómeno burocrático naciendo entonces los verdaderos y auténticos estatutos de funcionarios.

El término Función Pública suele ser percibido desde tres aspectos, los cuales, de manera íntegra, satisfacen globalmente el concepto de que trata el presente artículo. Esos aspectos son: En sentido general, desde el ángulo del recurso humano y desde la relación laboral.

Referente al sentido general, usamos la acepción estudiada para referirnos a aquellas acti- vidades que se encuentran exclusivamente en cabeza del Estado, desde el recurso humano, se entiende como las acciones desempeñadas por los funcionarios públicos, los cuales representan el Estado, y desde la relación laboral, las actividades entre el Estado y los particulares que se traduce en un servicio público, mas no función pública, aspecto este que fundamentaremos más adelante en base a señalamientos del Consejo de Estado.

En Colombia, la función pública como actividad en cabeza del Estado se remonta hacia el año de 1938 mediante la ley 165, por la cual se crea la carrera administrativa, hasta la existencia del decreto ley 3135 de 1968 en donde se consolida esta evolución de la función pública. De hecho con la consolidación del Estado social de derecho con la constitución de 1991, la función pública adquiere un trato de especial importancia hasta el punto que cerca de la mitad de los 380 artículos que conforman nuestra Constitución, contienen disposiciones de función pública.

Al efectuar un escrutinio al término Función Pública se establece que se refiere a una actividad del Estado, es decir, el Estado actuando. Más a fondo seria explicar académicamente el esencial alcance de las dos acepciones que conforman dicho término, pues para ello el Consejo de Estado (Sentencia ACU 1999) presentó la siguiente correspondencia entre las dos acepciones de Función Pública.

Según el Diccionario de la Lengua Española de la Real Academia Española, el término "función" significa "capacidad de acción o acción propia de los seres vivos y de sus órganos y de las máquinas o instrumentos; capacidad de acción o acción propia de los cargos y oficios"; por su parte, el vocablo 
"público" se define como "aplicación a la potestad, jurisdicción y autoridad para hacer una cosa, como contrapuesto a privado".

En palabras del Consejo de Estado:

En efecto, función pública es toda actividad ejercida por los órganos del Estado para la realización de sus fines y, excepcionalmente, por expresa delegación legal o por concesión, por parte de los particulares; pero, "es de señalar que la función pública significa una actividad de Estado que no puede jamás concebirse como análoga a la de un particular, aun cuando se tratara de una empresa; por manera que no resulta acertado deducir que toda prestación de un servicio público comporta el ejercicio de función pública, aunque, en ocasiones, bien puede existir coincidencia entre el ejercicio de ésta y la prestación de aquél, como sería el caso, por ejemplo, de los particulares transitoriamente investidos de la función de administrar justicia como conciliadores o árbitros (artículo 116 Constitución Política); o los particulares que bajo las condiciones del artículo 269 constitucional, sean encargados de ejercer el control interno de las entidades públicas; o la función notarial que desempeñan los particulares (artículo $1^{\circ}$ Decreto 960 de 1970); o las funciones de registro mercantil (artículos 26 y 27 del Código de Comercio) y registro de proponentes (artículo 22 Ley 80 de 1993) confiados a las cámaras de comercio, etc.

Luego en el presente trabajo al hablar de función pública, nos referiremos a la actividad ejercida por los órganos del Estado para la realización de sus fines indistintamente de la prestación de un servicio público, pues aunque ambas, por mandato constitucional, en su ejercicio, deben buscar la finalidad del Estado, esta última no se considera función pública.

De otro lado, la Carta Iberoamericana de la Función Pública nos dice al respecto:

La función pública está constituida por el conjunto de arreglos institucionales mediante los que se articulan y gestionan el empleo público y las personas que integran éste, en una realidad nacional determinada. Dichos arreglos comprenden normas, escritas o informales, estructuras, pautas culturales, políticas explícitas o implícitas, procesos, prácticas y actividades diversas cuya finalidad es garantizar un manejo adecuado de los recursos humanos, en el marco de una administración pública profesional y eficaz, al servicio del interés general. En el ámbito público, las finalidades de un sistema de gestión del empleo y los recursos humanos deben compatibilizar los objetivos de eficacia y eficiencia con los requerimientos de igualdad, mérito e imparcialidad que son propios de administraciones profesionales en contextos democráticos.

Siendo ello así, lo anterior citado refleja en parte el concepto de función pública en los artículos 122, 123, 124 y 125 de la constitución política, entre otros, pues el primero contempla la relación empleo - funciones, el segundo la significación y categorización de servidores públicos y el régimen aplicable, mediante ley, a los particulares que temporalmente desempeñen funciones públicas y regulará su ejercicio, el tercero, la responsabilidad, mediante ley, aplicable a los servidores públicos, y el cuarto lo referente a empleos de carrera.

De igual manera se pueden analizar, entre otros, los artículos 150 - 23, 209, 228y 267 con respecto al término función pública que contempla la 


\section{Héctor Turizo Tapias}

Constitución. Explico detalladamente, que todo ello debe desembocar en una administración pública profesional y eficaz, como parte de la organización y direccionamiento al servicio del interés general, como así lo encarna el deber ser de la función pública, sin embargo las políticas públicas y el poder de gestión se mimetiza por la contundente acción imperial de la politiquería que de verdad ha desteñido la institucionalidad en Colombia, máxime cuando se trata de la administración pública como actividad del Estado.

Caso diferente acontece con los artículos 48, 49 y 67 de la constitución política, entre otros, los cuales se refieren a un servicio público y como servicio público son una "específica competencia" de la administración pública, pues en este caso no comporta el ejercicio de "función pública”, salvo, aquellas citadas en palabras del alto tribunal, en donde bien puede existir coincidencia entre el ejercicio de función pública y la prestación de un servicio público, como el caso del artículo 116 cuando se refiere a que los particulares pueden ser investidos transitoriamente de la función de administrar justicia en la condición de jurados en las causas criminales, conciliadores o en la de árbitros habilitados por las partes para proferir fallos en derecho o en equidad, en los términos que determina la ley.

De igual forma acontece con el artículo 269, cuando se autoriza la contratación con empresas privadas para la prestación del servicio de control interno en las entidades públicas.

En base a lo anterior, el ámbito de la función pública involucra dos fundamentales variables, el empleo y las funciones. Estas variables resaltan el mandato constitucional radicado en el artículo 122, que señala: "No habrá empleo público que no tenga funciones detalladas en ley o reglamento", por supuesto el fondo sustancial que contiene el citado artículo nos señala que:

- Los empleos públicos de cada entidad deben estar contemplados en su planta de personal, la cual tiene fundamento en el artículo 189 numeral 14, para el orden nacional y en los artículos 305 numeral 7 y 315 numeral 7 para el orden territorial, Gobernaciones y Alcaldías, respectivamente.

- Las funciones y requisitos generales de los empleos están definidos en la ley. Para el orden nacional, se encuentran en el Decreto Ley 770 de 2005 y para el orden territorial en el Decreto Ley 785 de 2005. Cada entidad deberá establecer su propio manual específico de funciones y requisitos, según lo contemplado en el artículo $9^{\circ}$ del Decreto 2539 de 2005 en el cual se establecen las competencias laborales generales para los empleos públicos de los distintos niveles jerárquicos de las entidades a las cuales se aplican los Decretos Ley 770 y 785 de 2005. (Cartilla laboral DAFP. 2009. P, 13).

Dentro de la secuencia argumentativa de la temática, se hace necesario establecer la definición de empleo, por tanto conforme al artículo 19 de la ley 909 de 2004 se tiene:

Por empleo se entiende el conjunto de funciones, tareas y responsabilidades que se asignan a una persona y las competencias requeridas para llevarlas a cabo, con el propósito de satisfacer el cumplimiento de los planes de desarrollo y los fines del Estado. (Ley 909, $\operatorname{art19)}$

El señalamiento de la ley determina tajantemente, que de manera inherente el empleo lleva un conjunto de funciones, que son función pública, con el desnudo propósito de satisfacer el cumplimien- 
to de los fines del Estado y los planes de desarrollo, siendo ello así, la burocracia tiene un alto significado en el compromiso del cumplimiento de los fines del Estado, ello bajo en fiel sentido que se tiene según Webber. Sin embargo, la burocracia en muchos casos no asume ese compromiso de los fines del Estado quedándose entonces los fines del Estado en una maleza administrativa que no conduce a la satisfacción plena de las demandas societales, ello constituye un problema jurídico que se irá desmenuzando.

De hecho siendo a la sazón la función pública esa actividad ejercida por los órganos del Estado, nos muestra evidentemente cómo el empleo, por principio constitucional, no puede existir si no se tienen detalladas las respectivas funciones, y las funciones de los empleos deben estar dirigidas a contribuir al logro oportuno y eficaz de los cometidos a cargo del Estado, por tanto para el caso específico que estamos tratando se señala:

Así, entonces, en la Constitución Política se usa la expresión "función pública" o su plural "funciones públicas" para denotar aquellas actividades de interés general cuya titularidad corresponde al Estado soberano y que tienen como finalidad el cumplimiento de los fines esenciales del Estado. (Hernández 2008. P, 11).

Se sintetiza entonces, que el empleo se asienta sobre funciones preestablecidas, y las funciones deben estar diseñadas de acuerdo a la naturaleza del empleo con el propósito de satisfacer el cumplimiento de los planes de desarrollo y los fines del Estado, por ello son función pública, por ello las funciones al ser ejercidas por los servidores públicos muestra el Estado actuando.

A merced de ello, es preciso detallar, que la Constitución política maneja el termino función pública con dos significados diferentes, el primero, "apunta a las actividades cuya titularidad está reservada al Estado, que están relacionadas con el ejercicio de su soberanía y corresponden al interés general que este representa", el segundo, "como el conjunto de principios y disposiciones que rigen las relaciones laborales entre el Estado y los servidores públicos" (Hernández 2008. P, 12). Estos dos significados diferentes se deben mantener separados el uno del otro. Por tal razón debe entenderse que hay muchas funciones públicas, pero no todas son" función pública". Se describe entonces el término función pública, dentro del derecho público colombiano, como una expresión homófona, cuyo significado se propone individualizar para distinguir la magnitud de dicho término dentro de la administración pública.

Por todo lo señalado, se puede marcar la magnitud e importancia que porta la función pública dentro de la administración pública en lo que respecta al cumplimiento de los fines del Estado dentro de un Estado social de derecho, pues si bien de normatividad somos muy experto, él ejercicio de la función pública debe atender la efectividad en la articulación productiva de los elementos que hacen real, eficiente y eficaz ese ejercicio, y es precisamente la función pública, como actividad propia del Estado, la que en si ejercicio manifiesta esa articulación de transición entre el manual especifico de funciones y competencias laborales, el empleo, que amerita funciones para su existencia, pues las funciones son función pública y el servidor público quien al cumplir con sus funciones esta frente a las finalidad del Estado.

Lo así expuesto nos lleva, indefectiblemente a determinar, que la función pública, es decir, el Estado actuando, es fundamento esencial de la administración pública, pues no se puede negar 


\section{Héctor Turizo Tapias}

desde ningún punto de vista que la administración pública en su ejercicio deba alejarse o permita alejarse de la búsqueda de los fines del Estado.

De hecho existe, como se ha sostenido, una fuerte y sincrónica relación que permite en el ejercicio de la función pública como actividad propia del Estado, que entre los elementos manual de funciones, empleo, y servidor público, fluya esa transición con su alto compromiso de frente al Estado. Sin embargo, ello no se alcanza en nuestro modelo administrativo público, pues de verdad dicha fuerte y sincrónica relación se diluye por acción de la politiquería reinante en las instituciones que a toda costa busca debilitar esa fuerte y sincrónica relación, desviando la finalidad del Estado al desarticular la relación de transición de los elementos manual de funciones, empleo y servidor público, para de esta forma enlodar la administración pública y por supuesto mostrar un modelo administrativo publico ineficiente e ineficaz a los principios constitucionales.

Frente a todos esos mandamientos constitucionales y conceptualizaciones, valdría la pena cuestionar, ¿Para que existe entonces el Estado?, ¿Para qué son las instituciones públicas?, ¿Para qué es el poder en Colombia?, ¿el comportamiento de la administración pública actúa bajo principios acordes a un Estado social de derecho y por supuesto cumplidora de los fines del Estado?, ello como problema de la investigación, con la finalidad de ubicarnos mejor en lo que la función pública, organización y direccionamiento, es fundamento esencial en la administración pública.

\section{De los manuales específicos de funciones y competencias laborales}

Referente al manual de funciones, primer elemento de la relación, acercaremos algunas definicio- nes para entender lo que encierra dicho manual.

Es un instrumento de trabajo que contiene el conjunto de normas y tareas que desarrolla cada funcionario en sus actividades cotidianas y será elaborado técnicamente basados en los respectivos procedimientos, sistemas, normas y que resumen el establecimiento de guías y orientaciones para desarrollar las rutinas o labores cotidianas, sin interferir en las capacidades intelectuales, ni en la autonomía propia e independencia mental o profesional de cada uno de los trabajadores u operarios de una empresa ya que estos podrán tomar las decisiones más acertadas apoyados por las directrices de los superiores (Posada 2015).

De otro lado, el Departamento Administrativo de la Función Pública lo define:

El Manual Específico de Funciones y de Competencias Laborales es una herramienta de gestión de talento humano que permite establecer las funciones y competencias laborales de los empleos que conforman la planta de personal de las instituciones públicas; así como los requerimientos de conocimiento, experiencia y demás competencias exigidas para el desempeño de estos.

Es, igualmente, insumo importante para la ejecución de los procesos de planeación, ingreso, permanencia y desarrollo del talento humano al servicio de las organizaciones públicas. (DAFP 2016).

Al tratarse de temas de carácter público, nos inclinaremos por la definición que nos facilita la autoridad al respecto, como lo es el Departamento Administrativo de la función Pública.

Siendo ello así, se puede visualizar la importancia que encierra el Manual Especifico de Funciones y 
Competencias Laborales dentro de cualquier organización, máxime en este caso, al tratarse de entidades públicas, en donde dicho manual muestra la identificación del empleo, el procedimiento que lo asocia, las funciones y objetivos principales de ese empleo, los conocimientos esenciales y básicos que se deben tener para el desempeño del empleo, las competencias comportamentales y los requisitos de experiencia y estudios.

Ahora Fundamentado en la Norma Superior, su artículo 122, respecto al empleo, segundo elemento de la relación, determina, como antes se anotó:

No habrá empleo público que no tenga funciones detalladas en ley o reglamento, y para proveer los de carácter remunerado se requiere que estén contemplados en la respectiva planta y previstos sus emolumentos en el presupuesto correspondiente

Ningún servidor público entrará a ejercer su cargo sin prestar juramento de cumplir y defender la Constitución y desempeñar los deberes que le incumben.

Antes de tomar posesión del cargo, al retirarse del mismo o cuando autoridad competente se lo solicite deberá declarar, bajo juramento, el monto de sus bienes y rentas.

Dicha declaración sólo podrá ser utilizada para los fines y propósitos de la aplicación de las normas del servidor público. (Const. 1991, art.122)

Acorde al citado artículo, el Alto Tribunal Constitucional ha señalado:

Que cuando el artículo 122 exige fijar las funciones de los empleos públicos, entre otros actos por medio de reglamentos, no se está refiriendo exclusivamente a la ley que determina la estructura orgánica de la entidad pública, ni al manual general de funciones que expide el Presidente de la República, sino también al manual específico de funciones de cada entidad (Corte Constitucional, 2011).

Agregando a lo anterior, se normatiza esto del manual especifico de funciones y competencias laborales, por tanto se emitió entonces el Decreto 861 de 2000, derogado por el decreto 2772 de 2005 y este a su vez derogado por el decreto 1785 de 2014 "por el cual se establecen la funciones y los requisitos generales para los empleos públicos de los distintos niveles jerárquicos de los organismos y entidades del orden nacional y se dictan otras disposiciones" y el decreto ley 2503 de 1998 derogado por el decreto 770 de 2005, reglamentado parcialmente por el decreto 4567 de 2011 "Por el cual se reglamenta parcialmente la ley 909 de 2004 y el decreto ley 770 de 2005 ".

De igual manera se dictaron los decretos 2539 de 2005 "Por el cual se establecen las competencias laborales generales para los empleos públicos de los distintos niveles jerárquicos de las entidades a las cuales se aplican los decretos 770 y 785 de 2005"y el decreto 785 de 2005 "por el cual se establece el sistema de nomenclatura y clasificación y de funciones y requisitos generales de los empleos de las entidades territoriales que se regulan por las disposiciones de la ley 909 de 2004".

En el concurso de las diferentes normatividades se ha dejado en claro, que las funciones son inherentes al cargo, es decir a la estructura, y no al empleado, en palabras exactas "Las funciones son de los empleos, no de los empleados. (...) 


\section{Héctor Turizo Tapias}

Por ello, las entidades públicas disponen de un manual de funciones por cargo, no de un manual de funciones por empleado." (Hernández 2004. p, 35). Por esa suficiente razón:

En un sentido restringido se habla de función pública, referida al conjunto de principios y reglas que se aplican a quienes tienen vínculo laboral subordinado con los distintos organismos del Estado. Por lo mismo, empleado, funcionario o trabajador es el servidor público que esta investido regularmente de una función, que desarrolla dentro del radio de competencia que le asigna la Constitución, la ley o el reglamento (Corte Constitucional, 1998)

En sencillas palabras, el reglamento está entendido como el manual de funciones, luego el servidor público está investido de esas funciones con la finalidad de contribuir al logro oportuno de los acometidos obligados del Estado a través de esas funciones asignadas al empleo mediante el citado manual. En efecto las funciones desarrolladas por todos los servidores públicos se traducen como el Estado actuando, puesto, como se ha sostenido, las funciones son función pública, sin embargo en el ejercicio de la administración pública, es esa articulación de transición, Manual de Funciones, Empleo y Servidor Público, la que no se manifiesta, en muchos casos, conforme a la espiritualidad de las normatividades tratadas, lo que hace desviar el sentido del actuar del Estado, entrando en ineficiencias e ineficacias en la manera obligante y suprema de atender, desde el poder, las necesidades de la comunidad, por lo que la función pública, organización y direccionamiento como fundamento esencial de la administración pública se destiñe, luego ello es un problema jurídico manifestado en la administración pública.
Agregando a lo anterior, el concepto de "servidor público" incrustado en la Constitución de 1991, se entiende como un concepto genérico que incluye a todas las personas que están al servicio del Estado y de la comunidad, pues ello indica que el ejercicio del poder público tiene como razón de ser el logro de los fines de la sociedad y del Estado y por supuesto no el beneficio personal, entonces el ejercicio del poder público debe ser una función pública en el que los gobiernos de turno ejerciten su poder con miras de lograr la finalidad del Estado.

Ahora, refiriéndonos a la especificidad de lo público, Di Pego (2006) se refiere así. "Es decir, el espacio público es más amplio que el espacio político, por lo cual este último comparte todas las características del espacio público pero con alguna especificidad que al mismo tiempo lo distingue de éste" (Párrafo 16). Sin embargo en nuestro caso suele suceder que el espacio político asume la totalidad del espacio público desnaturalizando su amplitud y sentido, por lo que se cambia entonces la dirección de la finalidad del Estado y es lo que obstaculiza el ordenamiento constitucional en el ejercicio de la administración pública

Al profundizar en la dimensión de la función pública, en el Estado Colombiano todos los órganos de las ramas del poder púbico, al igual que los órganos autónomos e independientes para el cumplimiento de las demás funciones del Estado, tienen la obligación de diseñar el Manual Especifico de Funciones y Competencias Laborales, soporte técnico que justifica y da sentido a la existencia de los empleos dentro de las organizaciones, con la finalidad de dar estricto cumplimiento a lo ordenado en el artículo 122, arriba citado, para determinar de manera reglada conforme a la naturaleza del respectivo empleo, 
las actividades a desarrollar, todo en base, al cumplimiento de las fines esenciales del Estado.

Por su ineludible importancia dentro de la función pública cabe decir que el Manual Especifico de Funciones y Competencias Laborales atiende a un sólido marco legal que relaciona, entre otras, la Constitución Política, Artículos 122, $124,125,126,127,128,129$ y 130, Ley 909 de 2004, Decreto 785 de 2005, Decreto 2539 de 2005, Decreto 2772 de 2005, Decreto 2489 de 2006, Decreto 1018 de 2007, decreto 2484 de 2014 y Decreto 1785 de 2014. De igual manera la función pública se rige por unos principios constitucionales puntualizados en la ley 909 de 2004 artículo $2^{\circ}$, los cuales son, transparencia, eficacia, moralidad, merito, igualdad, economía, imparcialidad, publicidad y celeridad.

Ahora, los Manuales de Funciones Especificos de Funciones y Comtpetencias Laborales, deben elaborarse de acuerdo con el marco general que para las instituciones del orden nacional está contemplado en Decreto Ley 770 de 2005 y en los decretos reglamentarios 2539, 2772 de 2005 y 4476 de 2007 y para el orden territorial en el Decreto Ley 785 de 2005 y en el decreto reglamentario 2539 del mismo año, tal y como lo reza la Circular Externa No 100 - 003 de febrero 25 de 2009 emanada del Departamento Administrativo de la Funcion Publica - DAFP. Por tal razon, en sentido general, la función pública es un fundamento esencial en la administración pública.

Entonces lo que se pretende con el Manual de Funciones por Competencias Laborales, es que este sea el marco de reseña para conocer lo que esencialmente, conforme a la naturaleza de la entidad, deben, de manera particular, desarrollar cotidianamente los servidores públicos de la Entidad ya sean estratégicas, misionales de apoyo y de mejoramiento.

De igual manera sus contribuciones individuales y criterios de desempeño manifiesten de manera clara, la forma en que esos servidores aportan y dan cumplimiento a la misión que confiere la Constitución Política de Colombia a las instituciones del Estado.

Evidentemente esas contribuciones y criterios de desempeño se dan con la finalidad de consolidar un modelo de gestión por competencias que demuestre la integralidad de los procesos y que a través de la ejecución de esos procesos se evalúe realmente el desempeño y se establezcan los perfiles ideales que debe poseer un funcionario de cualquier administración u organización a fin de manifestar con efectividad y claridad sus responsabilidades y funciones adjudicadas a partir de su posesión e ingreso al servicio público.

Cabe decir entonces, con mucha razón, que la ley 909 de 1994 establece de manera inequívoca que la función Pública en Colombia debe administrarse bajo tres principios fundamentales como son en primer lugar los principios constitucionales de igualdad, mérito, moralidad, eficacia, eficiencia, economía, imparcialidad, celeridad, trasparencia, economía y publicidad; en segundo lugar, la debida ejecución de procesos de selección de personal cimentado en el mérito; y en tercer lugar la función Pública, la cual debe estar alineada hacia la prestación ordenada del servicio y a la satisfacción del bien común.

Referente a lo anterior, si bien es cierto el principio constitucional del mérito es de suma importancia cuando se trata de la eficiencia y efi- 


\section{Héctor Turizo Tapias}

cacia de la función pública, no menos cierto es que algunos estudiosos del tema lo consideran como un sofisma, al respecto se cita:

De algo sirve el sofisma de la mentirocracia, como en alguna oportunidad lo expresó en su columna de El Espectador el doctor Ramiro Bejarano Guzmán, con quien comparto su apreciación, y hoy la ratifico en este documento, en el sentido de que los procesos que para la época adelantaron las firmas consultoras contratadas para llevar a cabo los procedimientos de selección por parte del Ejecutivo fueron poco confiables y transparentes. Finalmente resulta paradójico que la ley de carrera que no involucre a los ministros, directores, gerentes, rectores, superintendentes, viceministros, subdirectores, subgerentes, vicerrectores, secretarios generales, directores de gestión, secretarios de despacho como gerentes de lo público, cuando de conformidad con sus funciones son quienes dirigen, conducen y fijan las políticas institucionales. Entonces cabe preguntarse quiénes son los que dirigen el Estado colombiano, y afirmar que la gerencia pública en Colombia no deja de ser una falacia en lo público. (Universidad Externado de Colombia, 2006)

De manera concreta la función pública, entiéndase además de la actividad propia del Estado, el manejo de la organización y direccionamiento, que involucra, en su operatividad, los elementos Manuales Específicos de Funciones y Competencias Laborales, el cual como asiento pormenorizado de las funciones, dan vida operativa al empleo, el mismo empleo, puesto que ellos forman el sistema operativo, por así decirlo, de la administración pública como actividad del Estado, y por supuesto el servidor público, lo que indica que ineficiencias e ineficacias en la operatividad en alguna de sus partes, de hecho desubica el sentido primordial de la administración pública como actividad del Estado.

Lo así detallado, indefectiblemente, genera un problema jurídico, puesto que la administración publica en su actuar debe guardar los principios acordes a un Estado social de derecho, y de hecho cumplir los fines del Estado, aspectos estos que tienen la connotación de constitucionales.

Esa desarticulación, reiteradamente expuesta, ha originado el permeado modelo administrativo público sin organización ni direccionamiento en su alto sentido de la manifestación de los fines del Estado. Entonces existe, como también reiteradamente se ha sostenido, una fuerte y sincrónica relación entre los citados elementos, lo que permite, dentro del deber ser, una transición de la función pública, como actividad del Estado, a las funciones contempladas en los Manuales como actividad de los servidores públicos, al empleo y a los servidores públicos, quienes en su actividad tienen en alto compromiso con la finalidad del Estado.

\section{La administración pública y la función públi- ca}

La administración pública como tal, tiene en su ámbito un solo objeto de estudio que se traduce en la actividad organizada del Estado. La función pública, como uno de los elementos centrales de la articulación de los sistemas político - administrativos, debe estar muy distante de la mentirocracia y mucho más de la plutocracia, pues son estas, inyecciones que han estado permeando el modelo administrativo público ante el estado maniatado de los responsables de la organización y direccionamiento de la función pública, pues el mérito, desempeño y capacidad son simples mu- 
letillas retoricas que la acción política ha implantado como principio generando la poca efectividad e ineficiencia de la acción pública social ante las demandas societales en este Estado social de derecho. Por tal razón la función pública debe ser atendida como fundamento esencial de la administración pública

Siendo ello así, nuestra constitución de 1991 es concreta cuando en sus artículos $2^{\circ}$ y 366 detalla los fines esenciales y las finalidades sociales del Estado, mandato constitucional este que involucra de inmediato a los servidores públicos en todas sus categorías y niveles, puesto que sus actividades deben comulgar con esos principios constitucionales para poder llegar a la satisfacción de la comunidad.

En efecto, la administración pública no es algo simple de comprender si se atiende al calificativo de lo Público, por tanto, debe entenderse como:

Aquella función del Estado que consiste en una actividad concreta, continua, práctica y espontánea de carácter subordinado a los poderes del Estado y que tienen por objeto satisfacer en forma directa e inmediata, las necesidades e intereses colectivos y el logro de los fines del Estado dentro el orden jurídico establecido y con arreglo a este (Machicado 2016)

Por supuesto que la administración público no es una rueda suelta que opera, es el contenido aplicativo de la interacción de transición entre la Función Pública, como actividad propia del Estado, el Manuel Especifico de Funciones y Competencias Laborales, que contiene las funciones que son función pública, el empleo, que debe su existencia a las funciones y el servidor público, que en su actividad, ejecutan las funciones, todo ello en la búsqueda de alcanzar la finalidad del Estado, y es esto el alcance que se tiene cuando se refiere a lo público, pues ello indica, como ya se ha dicho, estar sometida a los principios constitucionales y de ley, de lo contrario, bajo el sentido de organización y direccionamiento, ella deja de ser no solo administración, sino, que pierde el alto sentido de lo público.

En base a lo anterior, la administración pública en Colombia tiene obligaciones supremas con lo ordenado en la Carta Magna, por consiguiente la Corte Constitucional señala:

Surgen obligaciones concretas del postulado constitucional contenido en artículo $2^{\circ}$ Superior, según el cual dentro de los fines esenciales del Estado está "servir a la comunidad, promover la prosperidad general y garantizar la efectividad de los principios, derechos y deberes consagrados en la Constitución...". Con fundamento en esto, la jurisprudencia de esta Corte ha protegido el denominado "principio de eficacia de la administración pública”, según el cual las autoridades administrativas ostentan cargas relativas al desempeño de sus funciones, en orden a implementar y brindar soluciones a problemas de los ciudadanos. Dichos problemas constituyen deficiencias atribuibles a deberes específicos de la administración, y así las mencionadas soluciones han de ser ciertas, eficaces y proporcionales a éstos (Corte Constitucional 2009).

Por supuesto, claro está, que la administración pública está condicionada a cumplir con lo señalado en el preámbulo, el artículo $1^{\circ}$ y $2^{\circ}$ de la Constitución Política en lo que se denomina fines esenciales del Estado, como actividad cuya 


\section{Héctor Turizo Tapias}

titularidad corresponde con carácter exclusivo al Estado, ello sin desconocer el mandato constitucional de la finalidad social del Estado y de los servicios públicos, contemplados en los artículos artículo 365 y 366.

Luego al tratarse de un Estado Social de Derecho, el artículo 365 señala que "los servicios públicos son inherentes a la finalidad social del Estado", y el artículo 366 señala que "El bienestar general y el mejoramiento de la calidad de vida de la población son finalidades sociales del Estado”.

No queda duda entonces, que el bienestar general y el mejoramiento de la calidad de vida de la población, como finalidades sociales del Estado, son atendidas a través de la prestación del servicio público, pues mediante este se satisfacen las Necesidades Básicas de la población, lo cual es diferente a la actividad de la función pública, recordemos en palabras del consejo de Estado, ya citada, "no resulta acertado deducir que toda prestación de un servicio público comporta el ejercicio de función pública, aunque, en ocasiones, bien puede existir coincidencia entre el ejercicio de ésta y la prestación de aquél”. Y por supuesto con los fines expresados en el preámbulo de la constitución, que corresponden a un marco jurídico democrático.

Es conveniente recordar que desde mediados del Siglo XIX la administración pública como tal, comenzó a obtener su alineación como lo demuestra en la actualidad. Si bien el liberalismo en su versión NEO procuró subyugar la administración pública a su mínima expresión, con la finalidad de permitir la preeminencia de la libre competencia de la iniciativa privada, la baja regulación por parte del Estado y por supuesto la máxima aceptación de las libres fuerzas del mercado, por tanto, el desarrollo capitalista necesitó de la inter- vención del sector público, no solo para el mantenimiento del orden del consumo y la cimentación de una infraestructura en busca de disminuir la intensidad de la lucha de clases.

A raíz de ello, el ensanchamiento masivo de los servicios sociales estableció el llamado "Estado de Bienestar" facultado, para procurar mediante la administración pública, la educación, salud, trabajo y seguridad social, salvaguardar a todo individuo de la colectividad y a la colectividad misma.

Desde luego que hace necesario conocer de manera sucinta la historia de dicho Estado, desde una mirada económica.

La historia del Wellfare State, Estado de bienestar, toma cuerpo a partir de 1945. Por entonces, los países capitalistas desarrollados adoptaron la política del "Informe Beveridge" (suavizar las desigualdades sociales, redistribución de la renta, seguridad social, subvenciones estatales) y pusieron en práctica la teoría económica keynesiana (avivar la demanda) defendida por los socialdemócratas. Se llega a esta actuación por lucha obrera, por filosofía política, por interés en que hubiera paz social y también por la existencia del socialismo marxista en los países del este europeo. Como se ve, los nombres del economista y político británico Lord William Henry Beveridge (1879-1963) y de su compatriota John Maynard Keynes, están muy unidos a esta nueva concepción del Estado. Tesis políticas del Estado de bienestar: Muchos son los apelativos que ha recibido esta forma de entender el papel del Estado. Algunas de ellas indican un juicio (positivo o negativo) por parte de quien habla. Se le ha llamado "Estado Interventor", "Estado Providencia", "Es- 
tado Benefactor" e, incluso, "Papá Estado". La denominación más frecuente es "Estado del Bienestar" o "Estado Social de Derecho" (Banrep 2015).

Conforme a la cita, la Constitución de 1991 establece el Estado social de derecho, de allí que en ella florezcan un buen número de derechos fundamentales que se dirigen a la finalidad del Estado, luego, el andamiaje de la administración pública, y por supuesto del Modelo administrativo público, debe estar dirigido preferentemente a que las instituciones logren la finalidad del Estado mediante el fiel cumplimiento, de parte de los servidores públicos, de esa función pública.

En concordancia con lo dicho, como ampliación argumentativa, la Función Pública como término, se ha reseñado usualmente al empleo público, es decir, desde la actividad misma que ejerce la persona como servidor público al cumplir unas funciones que debe tener cada empleo. Sin embargo a estas alturas de cambios paradigmáticos la Función Pública, en palabras de la Procuraduría General de la Nación, tiene una connotación de un alto interés ya que se somete a una significación más desarrollada y compleja que atiende ineludiblemente a la forma de dar respuestas a las exigencias del entorno, de la Modernización de la administración pública, en los niveles centrales y territoriales. Por tal razón Función Pública inquiere suscitar empujes desde la prevención con la finalidad que las reformas a la administración, se dirijan hacia la eficiencia, eficacia y economía de la acción administrativa.

En virtud de lo anterior, la función Pública no sólo es tomada en su acepción formal, sino que también es vista con un criterio finalista, es decir, se toman en cuenta además de las funciones que los servidores públicos deben cumplir de acuerdo con la constitución y la ley, los resultados y el impacto obtenido con la ejecución de las mismas. De esta manera, la función pública es equiparada con principios de "buena gobernanza", en la medida en que implica que con el cumplimiento de dichas funciones se logren los objetivos para las cuales estas funciones fueron diseñadas.

Al abordar entonces la administración pública desde una visión mucho más general, esa administración se enmarca dentro de un Modelo Administrativo Publico, que no es otra cosa que el determinar la actividad del Estado mediante esa interacción de transición entre los elementos Manuel Especifico de Funciones y Competencias Laborales, Empleo y el servidor público de un lado, y de otro lado el cumplir esas disposiciones que rigen la relación laboral entre el Estado y el servidor público con la finalidad de que ese Estado allegue sus fines esenciales a la comunidad, pues ello debe ser el actuar de la Administración Pública y por ende la característica y actitud del modelo administrativo público .

En este aparte de la temática, es donde la función pública, como actividad solo en cabeza del Estado, como organización y direccionamiento, entra en su más vulnerada y cuestionada etapa dentro de la administración pública, puesto que la administración pública ha presentado deficiencias en su operatividad como actividad general del Estado, en el sentido de que la interacción de transición entre la el Manuel Especifico de Funciones y Competencias Laborales, el Empleo y el servidor público, no ha permitido, en muchos casos, que se alcancen las finalidades del Estado, descarriando por supuesto, la función pública hacia otras finalidades afectando de hecho la administración pública y desviando el Modelo Administrativo Publico que no logra la plena ejecución 


\section{Héctor Turizo Tapias}

de los fines del Estado al ejecutar los Planes de Desarrollo como compromiso para y por la comunidad.

Ante esta realidad de a puño, el legislativo presionado, inició una gestión de renovación de la administración pública en la búsqueda de encausar en el deber ser, el Modelo administrativo público, sin embargo, no se alcanza aún ese logro, pues no se ha dado una eficaz y eficiente lucha contra la corrupción en la administración pública, pues, al parecer, no se ha dado una participación activa al DAFP y a su adscrita la ESAP, en el diseño de políticas públicas firmes en cuanto a la organización y direccionamiento de la administración pública, atendiendo a la interacción de transición, ya que la corrupción en la administración pública, no es solamente una acción penalizada bajo la figura de delito, sino que se manifiesta fuertemente como un sistema de poder alternativo frente al sistema democrático de poder, que determina un conflicto de intereses, que por supuesto, enturbia salvajemente dicha administración, y en efecto, echa abajo el normal funcionamiento del procedimiento que exige el Estado social de derecho.

La citada realidad desdibuja la función pública, al golpear los manuales de funciones, pues las funciones de cada empleo son la actividad de los servidores públicos y con ellas se busca la finalidad del Estado dentro de la administración pública, ya que las funciones son función pública, es el Estado actuando, por tanto estremece el empleo y por ende debilita el fiel compromiso del servidor público para con los fines del Estado desmejorando la administración pública.

A raíz de ello, y con suficiente conocimiento de la comunidad, Colombia está viviendo momentos amargos a raíz de la imperiosa y funesta relación corrupción - administración pública, pues la transición, ya descrita entre los elementos Manual Especifico de Funciones y Competencias Laborales, empleo y servidor público, no opera en el deber ser.

Aquella funesta relación, al parecer legitimada, han imposibilitado el logro de los principios y los objetivos del Estado Social de Derecho, por la forma como la administración pública se ha ido llevando a cabo, lo cual de hecho reducen el respeto por las instituciones deteriorando la confianza ciudadana, y ayudando a debilitar la legitimidad del Estado social de derecho, ello es indefectiblemente un problema jurídico puesto que la administración pública en su actuar no guarda los principios acordes a un Estado social de derecho, y de hecho cumplir los fines del Estado.

El citado fenómeno se agiganta en las entidades territoriales, en donde los planes de desarrollo se convierten en una programación de contrataciones cuyo fin es satisfacer el interés particular con la finalidad de mantener la hegemonía politiquera. Todo ello, introducido en la sociedad, envolviendo al sector público, al sector privado y a la misma ciudadanía que en su apatía política, no ha hecho otra cosa que permitir que continúe reinando el caos. En palabras más sencillas, el fenómeno de la corrupción en la administración pública, es un efecto de esa funesta relación que ha impedido la libre transición en la operatividad de esos elementos, como causa.

El germen patológico de la corrupción en la administración pública en Colombia ha hecho metástasis en todos los sentidos de la estrella brujulear, pues de verdad se ha catalogado como un vicio generado en la colonia por acción de los criollos con la finalidad de mantenerse, pues ello fue la herencia que nos dejó la colonia. Al respecto Gamarra (como se citó en Zuleta 2015,) nos dice: 
El problema de corrupción en Colombia se puede ubicar con la misma formación de su Estado, inclusive desde antes si se tienen en cuenta los saqueos y las malas administraciones de la Real Hacienda durante la colonia. A nivel internacional, la preocupación por reducir el problema durante las dos últimas décadas ha cobrado renovada importancia, y Colombia no ha escapado a esa tendencia. El surgimiento de organizaciones y agendas especializadas en combatir el problema, reformas estatales en varios países y una creciente literatura académica sobre el tema son reflejo de ello. En Colombia, esto se tradujo en cambios a partir de la Constitución de 1991 y varias reformas en la mitad de la década que buscaron reducir los niveles del problema.

De igual manera, las acciones de la misma corrupción han hecho metástasis en muchas bases de la administración pública hasta el punto, como se ha dicho, de la pérdida de confianza en las instituciones del Estado, pues desde ha buen tiempo se viene tergiversando el término burocracia arrancándolo así de su noble origen weberiano, de tal forma que una de las deficiencias centrales en el modelo administrativo público, es precisamente la implantación peyorativa del término burocracia como acción dominante de la esfera política sobre lo público y que nos ilustra Alonso y Fernández (2016):

La burocratización ha sido uno de los procesos más criticados por los discursos neoliberales, pero lejos de eliminarse o desaparecer, se ha transformado y ha tenido objetivos distintos. Así, del principio de autoridad legítima socialmente regulada-típica del ciclo de gobernabilidad socialdemócrata- se pasa al de intercambio de intereses y recursos entre esferas públicas y privadas, legitimado por la mayor eficiencia y rentabilidad para todas las partes, y legislado a través de todo un sistema de normas de refuerzo estatal que favorezca el emprendimiento privado. Con este cambio en la filosofía de la intervención estatal, mucho más cercano a un Estado managerial que a un Estado social, se sustituyen las políticas públicas de construcción de tejido productivo y social por las políticas monetarias, de formación y movilización individualizada de recursos humanos, y de control de las demandas sociales. Pero estas políticas, lejos de suponer la desburocratización y horizontalización de la gestión estatal, construyen una nueva razón burocrática, donde el imperio de la norma sirve para construir una nueva gubernamentalidad de la hegemonía de lo mercantil sobre lo social.

Ante ello, de manera afanada el legislativo toma de nuevo acciones y entra, al parecer, a enfrentar dicha corrupción en la administración pública mediante leyes para fortalecerla, entre muchas otras, aparece la ley 790 de diciembre 27 de 2002 "Por la cual se expiden disposiciones para adelantar el programa de renovación de la administración pública y se otorgan unas facultades Extraordinarias al presidente de la República", la que en su artículo $1^{\circ}$ señala:

Artículo $\mathbf{1}^{\circ}$. Objeto. La presente ley tiene por objeto renovar y modernizar la estructura de la rama ejecutiva del orden nacional, con la finalidad de garantizar, dentro de un marco de sostenibilidad financiera de la Nación, un adecuado cumplimiento de los Fines del Estado con celeridad e inmediación en la atención de las necesidades de los ciudadanos, conforme a los principios esta- 


\section{Héctor Turizo Tapias}

blecidos en el artículo 209 de la C.N. y desarrollados en la Ley 489 de 1998.

Bien entendido se manifiesta el citado artículo de la ley en comento, ya que se orienta no solo a renovar y modernizar, sino de garantizar un adecuado cumplimiento de los fines del Estado dentro de un Estado social de derecho, lo que debe entenderse como la relación de transición de los elementos ya descritos de los elemento, sin embargo las medidas no han sido las mejores y día a día no se oye otra cosa que escándalos en la administración pública, ya que parece que los entes de control del Estado se han vuelto expertos en detectar anomalías, pero difícilmente en prevenirlas, y los responsables de la organización y direccionamiento de la función pública, en donde reina la genialidad teórica, a se han quedado maniatados.

Ahondando en lo anterior, la gestión administrativa dentro de la administración pública, debe buscar la eficiente y eficaz ejecución de la función pública, es decir, que la relación Función Pública, manuales de funciones, Empleo y servidor público en cuanto actividad se refiere, se lleve fielmente a cabo de manera sincrónica empleo por empleo conforme a su nivel jerárquico, de frente a sus respectivas funciones conforme a la naturaleza del empleo, y de igual manera se cumpla fielmente con las disposiciones que rigen las relaciones laborales entre el Estado y los servidores públicos para lograr el cumplimiento de los fines del Estado.

Bien se ha dicho anteriormente que las actividades de los servidores públicos, contempladas en el Manual Especifico de Funciones y Competencias laborales, no son acciones caprichosas, son por esencia y definición función pública, fundamento esencial de la administración pública, de igual manera, las disposiciones que rigen la relación laboral entre el Estado y los servidores públicos tampoco son caprichosas, pues dichas funciones y disposiciones están dirigidas hacia el cumplimiento de los fines esenciales del Estado. En efecto se ha desviado mucho el concepto esencial de la función pública permitiendo de esa forma desnaturalizarla la perdida de" fundamento esencial" para la administración pública.

A estas alturas de las exigencias, el entorno global hacia la administración pública, desde el ángulo visual del Ministerio Público, se tiene una concepción más amplia y compleja de lo que es la función pública, por ello dicha función debe indefectiblemente conducir hacia esas exigencias de la Modernización de la administración pública en todos los niveles.. "Por ello la Función Pública busca sembrar iniciativas desde la prevención que se dirijan a la reforma de la administración en dirección a la eficiencia, eficacia y economía en la acción administrativa" (Instituto de Estudios del Ministerio Público, 2015, P. 13). Sin embargo, la magnitud de la función pública, en sus dos significados o sentidos empleados por la constitución política no ha tomado el alcance que ello genera.

Ante la realidad que se vive, la administración pública en Colombia, frente a las anteriores directrices ,se evidencia que presenta vicios en el fiel cumplimiento y ejercicio de la función pública como fundamento esencial de la administración pública, auspiciado en gran parte, por la acción del reinante clientelismo que ha estado impactado negativamente sobre la administración pública desnaturalizando de un lado las actividades cuya titularidad corresponde al Estado y de otro lado ese conjunto de relaciones laborales entre el Estado y los servidores público, por consiguiente el Estado no ha estado respondiendo a sus fines esenciales, las autoridades no han mostrado su 
compromiso y responsabilidad frente al mandato constitucional y el poder en Colombia solo se da, en buena parte, para la lucha por el poder bajo una democracia, que independientemente del espectacular significado etimológico, es un sutil arte de mantener el poder.

Por supuesto que al comprometer de esa manera las funciones públicas y la función pública (Recordemos lo arriba citado, hay muchas funciones públicas, pero no todas son" función pública" ) han desestabilizado el Modelo Administrativo Público, que si bien tiene mucho por delante para continuar, deja un reto a la administración pública para que se atienda la ejecución de la función pública como lo ordena la espiritualidad de los principios Constitucionales en el cumplimiento de los fines esenciales.

Por tanto la función pública tiene tanta importancia dentro de la administración pública, que se ha demostrado con argumentos que es "fundamento esencial de la administración pública", pues exige de las gestiones gubernamentales en el cumplimiento de sus actividades, por lo menos mantener un equilibrio entre las demandas de la sociedad y esa capacidad de respuesta del gobierno, por tal razón la función pública es comparada con principios administrativos no solo de gobierno, sino de "buena gobernanza", que se entiende como ese proceso de toma de decisiones, y por supuesto, el proceso por el que estas son implementadas. Por todo ello el Estado está obligado por mandato constitucional a responder de manera eficiente y eficaz a la comunidad, no en vano el alto Tribunal Constitucional señala:

En síntesis, esta Corte ha concluido que el logro de la efectividad de los derechos fundamentales por parte de la administración pública se basa en dos principios esenciales: el de eficacia y el de eficiencia. A este respecto ha señalado que la eficacia, hace relación al cumplimiento de las determinaciones de la administración y la eficiencia a la elección de los medios más adecuados para el cumplimiento de los objetivos. En este sentido, ha sostenido que estos dos principios se orientan hacia la verificación objetiva de la distribución y producción de bienes y servicios del Estado destinados a la consecución de los fines sociales propuestos por el Estado Social de Derecho. Por lo tanto, la administración necesita un apoyo logístico suficiente, una infraestructura adecuada, un personal calificado y la modernización de ciertos sectores que permitan suponer la transformación de un Estado predominantemente legislativo a un Estado administrativo de prestaciones. (Corte Constitucional, 2013)

Fundamentado en lo anterior, obviamente se determina que la función pública en sentido general, no debe distorsionarse en sus dos significados cuando de finalidad del Estado se trata. No se puede ocultar que el modelo administrativo público es permisible para que se efectúen acciones de corrupción en los servidores públicos que golpeen contundentemente el alto compromiso para con las finalidades del Estado y se mantenga la esfera dependiente y parcializada de la acción de la función pública en el ejercicio de la administración pública, por lo que la función Pública, no se presenta alineada hacia la prestación ordenada del servicio y a la satisfacción del bien común. Ello en resumidas cuentas, muestra el fundamento esencial de la función pública en la administración pública.

\section{Conclusiones}

Las respuestas a las preguntas como problema de investigación, ¿Para que existe entonces el Es- 


\section{Héctor Turizo Tapias}

tado?, ¿Para qué son las instituciones públicas?, ¿Para qué es el poder en Colombia?, ¿el comportamiento de la administración pública actúa bajo principios acordes a un Estado social de derecho y por supuesto cumplidora de los fines del Estado?, se concluye:

El Estado, Persona jurídica de la nación, debe existir para la satisfacción de las necesidades públicas. Sin embargo, dentro de la administración pública, en buena parte, los significados que la Constitución Política emplea de la expresión "Función Pública" no se han tenido en cuenta a buena fe, de hecho las acciones públicas manifestadas por la administración pública, han estado alejadas de esos significados, desnaturalizando la magnitud de esa función pública y por supuesto impactando en la propia administración, que por ende, ha olvidado la obligación en el cumplimiento de los postulados constitucionales en cuanto a los fines esenciales y fines sociales del Estado, luego el Estado en su desempeño, en buena parte de los casos, no demuestra su plena y firme existencia hacia el cumplimiento de esos postulados, mientras que en otros casos no se llega hacia la solución de las demandas societales, pues se muestra que hay más territorio que Estado.

Desde luego las instituciones públicas, deben su existencia a la búsqueda de los fines esenciales, y la búsqueda de los fines del Estado, por ende deben permitir la relación transitiva entre el Manual Específico de Funciones y Competencias Laborales, el Empleo, y los Servidores públicos. Lo contrario irrumpe la normal y fluida transición entre esos elementos, lo cual desfigura la función pública bloqueando así la búsqueda de las finalidades del Estado, el servicio hacia los intereses generales.
El poder en Colombia, entiéndase político, debe manifestarse cumpliendo con los fines sociales, de igual manera la citada relación debe cumplir el deber ser. Caso contrario la transición no opera. Esta desnaturalización de la función pública a merced del catalizador clientelismo reinante en la administración pública, han entorpecido el fiel cumplimiento constitucional desestabilizando la actividad del Estado social de derecho permitiendo la concentración de riquezas, la impunidad, la falta de transparencia en la financiación política, debilidad en las políticas de Estado frente a la corrupción politiquera, por lo tanto, el fundamento esencial que porta la función pública dentro de la administración pública está siendo deformado de tal manera que el modelo administrativo público ha sido permeado.

El comportamiento de la administración pública debe actuar bajo principios acordes a un Estado social de derecho y por supuesto cumplidora de los fines del Estado. Por lo tanto la burocracia debe tomarse bajo el estricto sentido Weberiano. Sin embargo, ella, ha sido tomada peyorativamente por la esfera política sobreponiéndose a la esfera pública, lo que ha dejado en tela de juicio no solo la actividad de la burocracia, sino, la tan cacareada "meritocracia" que en la mayoría de los casos solo representa un adorno literario. El poder político en Colombia, en varios casos, está al servicio de otros intereses, ello, sin olvidar de paso el sentido de responsabilidad y pertenencia del Departamento Administrativo de la Función Pública - DAFP y su adscrita la Escuela superior de Administración Pública - ESAP, quienes han estado maniatados en la búsqueda de un sistema profesional y eficaz de la administración pública en lo que respecta a la organización y direccionamiento de esa para que los elementos, ya descritos, no solo se articulen, sino, que en el operar de esa articulación fluya la transición entre ellos 
de la esencia de la función pública y permita una óptima administración pública y de hecho un modelo administrativo acorde a las exigencias constitucionales y de ley .

La relación de hechos expuesta, constituye indefectiblemente un problema jurídico puesto que la administración pública en su actuar no guarda los principios acordes a un Estado social de derecho, y de hecho no alcanza a cumplir los fines del Estado, por lo cual la función Pública no se alinea hacia la prestación ordenada del servicio y a la satisfacción del bien común.

\section{Referencias bibliográficas}

Alonso y Fernández (2016). La burocracia neoliberal y las nuevas funciones de las normas. Encrucijadas, Revista crítica de ciencias sociales Vol 12

Banrepcultural (2015). Historia del Estado bienestar - Wellfare State.

Carta Iberoamericana de la Función Pública. Aprobada por la V Conferencia Iberoamericana de Ministros de Administración Pública y Reforma del Estado Santa Cruz de la Sierra, Bolivia, 26-27 de junio de 2003. Respaldada por la XIII Cumbre Iberoamericana de Jefes de Estado y de Gobierno Constitución Política de Colombia (1991) 2da edición Legis..

Congreso de la República (27 de diciembre 2002) Por la cual se expiden disposiciones para adelantar el programa de renovación de la administración pública y se otorgan unas facultades extraordinarias al presidente de la Republica [Ley 790 de 2002]

Congreso de la República (23 de septiembre 2004) Por la cual se expiden normas que regulan el empleo público, la carrera administrativa, gerencia pública y se dictan otras disposiciones. [Ley 909 de 2004]

Consejo de estado. Sección tercera. Sentencia ACU - 798 del 5 de agosto de 1999 [C.P. Germán Rodríguez Villamizar]

Corte Constitucional. Sala Plena. Sentencia C- 679 Del 14 De septiembre De 2011. [M.P. Mauricio González Cuervo].

Corte Constitucional. Sentencia C - 563 Del 7 De octubre De 1998 [M.P. Antonio Barrera Carbonell, Carlos Gaviria Díaz].

Corte Constitucional. Sala Octava De Revisión. Sentencia T - 733 Del 15 De octubre De 2009. [M. P. Humberto Antonio Sierra Porto].

Corte Constitucional. Sala Plena. Sentencia C - 826 De 13 De noviembre De 2013. [M.P. Luis Ernesto Vargas Silva].

Decreto 4567 de 2001, Por el cual se reglamenta parcialmente la Ley 909 de 2004 y Decreto-ley 770 de 2005. Del 1 de diciembre de 2011.

Decreto 2539 de 2005, "Por el cual se establecen las competencias laborales generales para los empleos públicos de los distintos niveles jerárquicos de las entidades a las cuales se aplican los Decretos-ley 770 y 785 de $200522 "$, de julio de 2005. 


\section{Héctor Turizo Tapias}

Decreto 2772 de 2005, "Por el cual se establecen las funciones y requisitos generales para los diferentes empleos públicos de los organismos y entidades del orden nacional y se dictan otras disposiciones", de 09 de agosto de 2005

Decreto 785 de 2005, "Por el cual se establece el sistema de nomenclatura y clasificación y de funciones y requisitos generales de los empleos de las entidades territoriales que se regulan por las disposiciones de la Ley 909 de 2004”, de 16 de marzo de 2005.

Decreto 1785 del 18 de septiembre de 2014, "Por el cual se establecen las funciones y los requisitos generales para los empleos públicos de los distintos niveles jerárquicos de los organismos y entidades del orden nacional y se dictan otras disposiciones", de 14 agosto de 2014

Decreto 2943 de 2006, "Por el cual se reglamenta el otorgamiento de concesiones de los servicios de telecomunicaciones que utilicen sistema de acceso troncalizado en las áreas de servicio departamental y municipal y se dictan otras disposiciones", de 31 de agosto de 2006

Decreto 1018 de 2007, "Por el cual se modifica la estructura de la Superintendencia Nacional de Salud y se dictan otras disposiciones.”, 30 de marzo de 2007

Decreto 1083 de 2015, "Por medio del cual se expide el Decreto Único Reglamentario del Sector de Función Pública", de 26 enero de 2016

Departamento administrativo de la función pública. (2015). Guía para establecer o modificar el manual especifico de funciones y de competencias laborales. Hernández Alfonso, P. (2008). Temas de función pública. Acepciones constitucionales de la expresión función pública. Bogotá D.C.: Imprenta distrital.

Di pego, Anabella (2006): Pensando el espacio público desde Hannah Arendt: Un diálogo con las perspectivas feministas. Memoria Académica. La plata, Argentina. Universidad Nacional de la Plata.

Hernández Alfonso, P (2004). Bases constitucionales de función pública - empleo público. Bogotá D.C.: Edit. Jurídica Gustavo Ibáñez

Instituto de Estudios del Ministerio Público - Iemp. (2015). Procuraduría General de la Nación. Bogotá D.C.

Mostato Machicado, M (2016). Derecho administrativo y la administración pública boliviana. Ed.:Catacora.

Zuleta Andrea Paola (2015). La corrupción su historia y sus consecuencias en Colombia (Tesis de posgrado) Universidad Militar Nueva Granada. Bogotá, D.C. Posada Serna, K. (2015) Manual de funciones y procedimientos. Tomado de: https://prezi.com/yq92hr7dcvnu/manual-de-funciones-y-procedimientos/ 